\title{
Initiative to Increment the number of Women in STEM Degrees: Women, Science and Technology Chair of the Public University of Navarre
}

\author{
Patricia Aranguren \\ Public University of Navarre \\ Pamplona, Spain \\ patricia.arangureng@unavarra.es \\ Alicia Martinez \\ Public University of Navarre \\ Pamplona, Spain \\ alicia.martinez@unavarra.es \\ Gurutze Perez \\ Public University of Navarre \\ Pamplona, Spain \\ gurutze.perez@unavarra.es
}

\author{
Idoia San Martin \\ Public University of Navarre \\ Pamplona, Spain \\ idoia.sanmartin@unavarra.es
}

Aranzazu Jurio

Public University of Navarre

Pamplona, Spain

aranzazu.jurio@unavarra.es

\author{
Marisol Gomez \\ Public University of Navarre \\ Pamplona, Spain \\ marisol@unavarra.es
}

\author{
Leyre Catalan \\ Public University of Navarre \\ Pamplona, Spain \\ leyre.catalan@unavarra.es \\ Silvia Diaz \\ Public University of Navarre \\ Pamplona, Spain \\ silvia.diaz@unavarra.es \\ Edurne Barrenechea \\ Public University of Navarre \\ Pamplona, Spain \\ edurne.barrenechea@unavarra.es
}

\begin{abstract}
The Public University of Navarre joined with Navarre Government has created the Women, Science and Technology Chair. This chair arises due to the plummeting tendency of the percentage of women in STEM degrees with the aim of reversing this trend. The programme of activities is defined throughout this contribution by six activities: a Theatre Play, a Poster Award on Final Degree/Masters Project, The 1st Week of Women, Science and Technology, the Promotion of Technical Degrees in schools and high-schools, a Workshop about Gender Stereotypes and the Fostering of Women among Science and Environment.
\end{abstract}

Each activity gained great success and the preset goals were highly accomplished, especially, the 1st Week of Women, Science and Technology activity. The latter achieved a great success both in participation and in repercussion, contributing to visualize the role of women in science and technology.

Keywords-STEM, Science Gender Gap, Technology, Stereotypes, Women Models, Gender Gap.

\section{INTRODUCTION}

The percentage of women who work in engineering fields is notably low $[1,2]$. In addition, the number of women enrolled in STEM degrees (science, technology, engineering and mathematics) is very low, and besides it has further decreased over the past few years [2-4]. This tendency reflects a paramount problem that affects globally. In Spain, at the Public University of Navarre the percentage of women in several engineering related degrees has drastically decreased, as an example in Electrical and Electronical Engineering the percentage dropped from the $20 \%$ in 2002 to the $12 \%$ in 2019.

The Women, Science and Technology Chair of the Public University of Navarre was founded in 2019 as a result of an agreement between UPNA and Navarre Government. Its aim focuses on increasing the participation of women in science and technology, boosting their presence in STEM degrees, and fostering research done on STEM fields including the gender perspective.

(C) 2020 IEEE. Personal use of this material is permitted. Permission from IEEE must be obtained for all other uses, in any current or future media, including reprinting/republishing this material for advertising or promotional purposes, creating new collective works, for resale or redistribution to servers or lists, or reuse of any copyrighted component of this work in other work.
The organizational structure of the Chair includes the Director of the Chair who is a lecturer and researcher at UPNA; a Steering Committee formed by two docents and researchers of UPNA (Vice-Director and Secretary) and two members of Navarre Government; and a Task Team formed by eight lecturers and researchers at UPNA. The Steering committee approves the programme of activities of the chair and the Task Team develops them.

This manuscript presents the programme of activities of the chair, focusing on the most relevant activity called the 1st Week of Women, Science and Technology. The aim of this week is to visualize the role of the women in science and technology. From Monday to Thursday discussion panels encompassing different fields were developed where women with recognized prestige were invited. To conclude the week, on Friday, the closing act took place.

\section{Programme OF ACTIVITIES}

The programme of activities of the Chair throughout 2019 is divided in a total of six activities, as Table I presents.

Activity 1, "Yo quiero ser Científica" (I want to be a Woman Scientist) is a theatre play where nine lecturers from the Public University of Navarre rescue the life and work of scientific women from the previous centuries. In this play, as the actresses are the actual researchers and lecturers who bring to life the historical characters, the girls who attend the play could identify and inspire themselves to increment their interest in science and technology. In other words, current women scientists rescue past female scientists to foster future women scientists. The historical characters represented are included in chronological order: the philosopher Alexandria Hypatia (370-415), the naturalist Maria Sibylla Merian (16471717), the mathematician Ada Lovelace (1815-1852), the mathematician Sofia Kovalevskaya (1850-1891), the physicists and chemist Maria Salomea Skłodowska-Curie (1867-1934), the mathematician Emmy Noether (1882-1935), the electrical engineer Edith Clarke (1883-1959), the programmer Klára Dán Von Neumann (1911-1963) and the inventor Hedy Lamarr (1914-2000). The play is aimed at students between the ages of 7 and 12 . 
TABLE I. Programme of activities of THE WOMEn, Science AND TECHNOLOGY CHAIR

\begin{tabular}{|c|c|}
\hline Activity 1 & "Yo quiero ser Cientifica" play \\
\hline Activity 2 & Poster Award on Final Degree/Masters Project \\
\hline Activity 3 & The 1st Week of Women, Science and Technology \\
\hline Activity 4 & $\begin{array}{r}\text { Promotion of technical degrees in schools and high- } \\
\text { scools with gender-based bias. }\end{array}$ \\
\hline Activity 5 & Workshop about gende stereotypes in early ages \\
\hline Activity 6 & Women, Science and Environment \\
\hline
\end{tabular}

Related to this activity, the students who attended the theatre play along the 2018/2019 academic course were given the opportunity to participate in the 1 st Contest "I want to be a Woman Scientist". This contest consisted on the presentation of an artistic work related to the topic of the theatre play, focusing on one or more women scientists of the past or present. The format of the work was free, accepting drawings, texts, videos or power points among others.

Activity 2 defines the " 1 st Poster Award on Final Degree/Masters Project (FD/MP)". This award recognized the best final degree or master projects developed by women at the Public university of Navarre during the 2018/2019 academic course in STEM studies. The competition had two modalities, one for the works developed in undergraduate studies and the other one for postgraduate studies. The candidates had to present a horizontal or vertical A0 $(120 \mathrm{~cm}$ $\mathrm{x} 90 \mathrm{~cm}$ ) size poster where the most important ideas of their works had to be included. The format had to be a pdf file which was afterwards printed in the original size to support their defense. The defense of the posters as well as the resolution of prizes was done during the closing act of the $1 \mathrm{st}$ Week of Women, Science and Technology. Further information of Activity 2 is detailed in Section III.

Likewise, the Chair organized the 1st Week of Women, Science and Technology (Activity 3), devoted to visualize women scientists and technologists. All the detailed information about Activity 3 can be found in Section III.

Regarding Activity 4, the Chair also developed activities for promoting STEM studies at gender-based biased schools and high-schools. This activity was focused on students aged between 14 and 18. The objective was to present, from the view point of several female lecturers, the technical degrees which are offered at the Public University of Navarre showing the importance of having women at those fields. Moreover, women who have studied those degrees and nowadays are professionals of the field took part at this activity.

Furthermore, the Chair organized a workshop oriented to teachers, educators and general public about gender stereotypes in early ages (Activity 5). The principal aim of this activity was to present the data about gender stereotypes in primary and secondary teaching. These data belong to the research of several lecturers and students from the Public University of Navarre.

The last activity focused on a program about Women, Science and Environment (Activity 6). The fostering of the vocation for science in the field of agronomical engineering was the goal of this activity, which trained researchers to be involved in ecology an environmental science in schools.

The following section includes a detailed overview of one of the main activities developed by the Chair, the 1st Week of Women, Science and Technology.

\section{III. $1^{\text {ST }}$ WEEK OF WOMEN, SCIENCE AND TECHNOLOGY}

The 1st week of Women, Science and Technology was celebrated between the 7 th and 11 th of October 2019. The aim of this week was to visualize the role of women in science and technology. Hence, several activities were programmed. From Monday to Thursday discussion panels on different fields were scheduled including the presence of women with recognized prestige in the different areas. In particular, the subject areas were: Teaching and Investigation, Entrepreneurship, Biomedical Engineering and Renewable Energies. The discussion panels were directed by different women from the Women, Science and Technology Chair. Table II includes the titles of the four sessions conducted within the week, the number of speakers and their profile (Entrepreneurial-E, Docent and researcher- DR).

The Monday session, entitled Women, Teaching and Investigation, counted with the presence of four women who belong to the teaching and investigation areas. This discussion panel was directed by a lecturer and researcher of the Public University of Navarre who belong to the Women, Science and Technology Chair. This session visualized the obstacles that the different speakers have had during their research or docent careers because of being women. Likewise, the contribution of the female talent into these ambits, the difference of conducting science or technology by men or women and the gender gap were presented during this session. Besides, the speakers gave their point of view on why the girls do not study STEM degrees and which solutions could increase the presence of women in those studies. The reasons why women do not reach leading posts in teaching and investigation at universities were also commented and widely discussed.

On Tuesday, the session entitled Entrepreneurship and Women gathered four women with professional careers related to entrepreneurship, specifically enterprise founders. This discussion panel was moderated by a lecturer and researcher of the Public University of Navarre who belongs to the Women, Science and Technology chair and is a founding member of a spin-off of the Public University of Navarre. This session visualized the women and the entrepreneurship. The speakers gave their point of view about the low percentage of entrepreneur women, the $19 \%$ of entrepreneur Spanish people are women whereas the $51 \%$ of the Spanish population belong to that gender. The differences when formulating the strategy to start a business were also discussed. Women prefer to do it alone while men opt for finding a funding partner. Among other aspects, the idea of men receiving more funding than women because of a well dominated world of men investors and women having a lower self-confidence when starting a new project despite having the same capacities of leadership were discussed. On the one hand, one conclusion obtained from that session was that a key word to reach equality when talking about entrepreneurship is "co-responsibility", meaning to share home duties and family care equally within the couple. On the other hand, another conclusion reached was that there should exist policies to increase the number of women leading any kind of enterprise.

The discussion panel celebrated on Wednesday, entitled Biomedical Engineering and Women, was formed by three women researchers on Biomedical Engineering, both related to teaching and investigation, as well as related to the enterprise world. The conductor of the discussion panel was a lecturer and researcher of the Public University of Navarre who belongs to the Women, Science and Technology Chair. 
TABLE II.

DISCUSSION PANELS

\begin{tabular}{|c|c|c|}
\hline Title of the session & $\begin{array}{c}\text { Number of } \\
\text { speakers }\end{array}$ & $\begin{array}{c}\text { Speakers } \\
\text { profile }\end{array}$ \\
\hline Women, Teaching and Investigation & 4 & DR \\
\hline $\begin{array}{c}\text { Entrepreneurship and Women } \\
\text { Biomedical Engineering and } \\
\text { Women }\end{array}$ & 3 & E \\
\hline Renewable Energies and Women & 4 & DR and E \\
\hline
\end{tabular}

The speakers commented when their interest in science started, specifically in topics related to health. Moreover, they analyzed the influence of being women on their personal and professional careers. During the debate some research studies were discussed where the results show that the perception of one's own intelligence affects the academic discipline selected. It appears that girls tend to think they are less intelligent as a response to the social conditions lived from very early ages. Furthermore, the figures of women and science in Spain were analyzed. The percentage of women $\mathrm{PhD}$ defenses is higher than that for men, however, the presence of women at postdoctoral stages decreases and this tendency follows along the professional career. The Spanish National Research Council (CSIC) states that a $58 \%$ of women start a scientific career, while only the $25 \%$ reach the higher steps. In other words, the percentage of women plummets as the scientific career promotes, not only in Spain but in the whole European Union. Also, the differences between women and men leading a project were also discussed. Finally, the speakers, as experts on medicine and genetics, gave their opinion about the difference between women and men when developing a job, considering if there really exists a genetic difference or it is the society the one which conditions the way of conducting a job by each gender.

The last session panel was celebrated on Thursday with the title: Renewable Energies and Women. This session was composed by four women with professional trajectories related to entities framed within the Renewable Energies field. The session was conducted by a lecturer and researcher from the Public University of Navarre and the Director of the Women, Science and Technology Chair. The actual state of the Renewables Energies and their prospective, as well as the role of the women in the Renewable Energies field were discussed along the session. During the first part of the debate, the general context of the implementation of the Renewable Energies, especially the wind and solar energies, was discussed. Besides, the technological and productive progresses which have allowed to reach the actual competitiveness of the generation of green energy in comparison to the generation based on fossil fuels were stated. To conclude this first part, the speakers gave their perspective about the future of Renewable Energies (market share, integration of storage, electrification of the transportation sector). The second part was centered on the women role in this field. The speakers provided their opinions form their own professional experience. They stated that the low percentage of women in the enterprises of the sector reflects the reduced number of women studying STEM degrees. Also, they related the influence of being women on their professional career. Finally, the conclusion of the session was done by the speakers with motivational quotes to animate new generations to opt for a professional career on Renewable Energies.

On Friday, the last day of the week, the closing act took place at the library of the Arrosadía Campus, the main campus of the Public University of Navarre. During the presentation of the closing act, the Director of the Women, Science and Technology Chair remarked the participation of more than 20 professional women who contributed with concluding remarks about their experiences and achievements in the research, Biomedical Engineering or Renewable Energies fields. The Dean of the Public University of Navarre acknowledged the work developed by the Chair as well as the sponsors who made possible this initiative, "and initiative which enables the launch of several activities directed to foster the vocation for science among women".

The closing act included the events detailed in Table III. On the one hand, the defense and resolution of the 1st Poster Award on Final Degree/Masters Project (Activity 2), as well as the performance of scientific monologists from the Zaragoza University. Moreover, the prize award ceremony of the two contests organized by the Chair: 1st Contest I want to be a Woman Scientist, associated to the homonymous activity (Activity 1) and the 1st Poster Award on FD/MP. Thirteen candidates participated at the latter contest. Their final projects were presented along the 2018/2019 academic year and they were developed within the science and technologies fields. The candidates had to defend their work to the panel in five minutes making reference to their poster. The panel was formed by three people, and could state questions to the candidate after their expositions. The following criteria had to be followed by the panel in order to consider the work of the candidates:

1. Quality and interest of the FD/MP: contribution to the science and technology fields

\section{Poster: conciseness, clarity and presentation.}

3. Explanation and answers to the questions raised by the panel: rigor in responding and capability to answer briefly to the technical questions of the work.

After the public defense and exposition, the panel decided the concession proposal throughout a report. A total of 9 Final Degree Projects and 4 Final Master Projects were presented and it has to be highlighted the high level of all of them, the quality of the technical insights as well as the communication skills of the participant were very high.

The first Vice-President and Counselor of the Presidency, Equality, Public Function and Interior of the Navarre Government, the Dean of the Public University of Navarre and the Director of the Women, Science and Technology Chair presided the award ceremony were the prizes for the 1st Contest I want to be a Woman Scientist and the 1st Poster Award on FD/MP were awarded. Moreover, the nine lecturers and researchers who embody women scientist form the past at the theatre play took part into the awarding of the $1 \mathrm{st}$ Contest I want to be a Woman Scientist dressed as the past scientists. As well, in this ceremony a well-known female singer and composer from Navarra took part.

This closing act also included a discussion panel entitled "Women in the World of the Future" were three lecturers and researchers of the Public University of Navarre and one docent, researcher and divulger of the University of the Basque Country took part. 

SCIENCE AND TECHNOLOGY

\begin{tabular}{|c|c|}
\hline Event 1 & $\begin{array}{c}\text { Defense and Resolution of the } \\
1^{\text {st }} \text { Poster Award on FD/MP }\end{array}$ \\
\hline Event 2 & Science Monologist \\
\hline Event 3 & Awards ceremony \\
\hline Event 4 & Discussion panel \\
\hline Event 5 & Concerts \\
\hline
\end{tabular}

The end of the closing act was a farewell concert where the invited singer interpreted at the piano several pieces of music. After her singing, the winner music group of the "Campus Music 2017" performed to close the acts of the $1^{\text {st }}$ Week of Women, Science and Technology and the acts of the $25^{\text {th }}$ Anniversary of the library of the Public University of Navarre.

\section{CONCLUSIONS}

As a conclusion, the newly created women, Science and Technology Chair has developed several activities looking to pursue its aim: increasing the participation of women in science and technology throughout their active presence in STEM degrees and the subsequent job and research positions. Each of the activities was defined and developed to reach that goal, especially the 1st Week of Women, Science and Technology which has been deeply developed along this contribution.

The main objective of the 1st Week of Women, Science and Technology was to visualize the women in science and technology fields, and this was accomplished thanks to the participation of more than 20 professional women in those fields. The variety of their professional careers let us know the role of women in fields such as teaching, investigation, entrepreneurship, Biomedical Engineering and Renewable Energies.

Moreover, this activity had a great impact, both due to the attendance rate to the different events and due to the media coverage. A total of 150 people attended the discussion panels while the closing ceremony held on Friday was attended by 400 people. Thanks to this assistance and the impact of the media, the goal of visualizing women in science and technology was successfully met.

In short, due to the success of participation and the press repercussion of the 1 st Week of Women, Science and Technology it can be concluded that this activity contributed to visualize the role of women in science and technology and consequently, contributed to foster future generations of women oriented to scientific and technological professional careers.

\section{ACKNOWLEDGMENT}

Authors are grateful to Navarre Government, Caja Navarra Foundation, Spanish foundation for Science and Technology (FECYT-Ministerio de Economía, Industria y Competitividad), Public University of Navarre, IEEE CAS Spain Chapter and the Chair in Renewable Energy of the Public University of Navarre.

\section{REFERENCES}

[1] B. I. Imasogie, G. M. Oyatogun and K. A. Taiwo, "Enhancing Gender Balance in Engineering Education and Practice," 2018 World Engineering Education Forum - Global Engineering Deans Council (WEEF-GEDC), Albuquerque, NM, USA, 2018, pp. 1-8.

[2] Bystydzienski, J. M., \& Bird, S. R. (Eds.). (2006). Removing barriers: Women in academic science, technology, engineering, and mathematics. Indiana University Press.

[3] Peixoto, A., González, C. S. G., Strachan, R., Plaza, P., de los Angeles Martinez, M., Blazquez, M., \& Castro, M. (2018, April). Diversity and inclusion in engineering education: Looking through the gender question. In 2018 IEEE Global Engineering Education Conference (EDUCON) (pp. 2071-2075). IEEE

[4] Roy, J (2019, July). Engineering by the numbers. American Society for Engineering Education 